\title{
Growth Inhibition of Acetobacter aceti by L-Threonine and L-Homoserine: the Primary Regulation of the Biosynthesis of Amino Acids of the Aspartate Family
}

\author{
By J. O'SULLIVAN \\ Institute of Microbiology, Swiss Federal Institute of Technology, \\ Universitätstrasse 2, 8006 Zürich, Switzerland \\ (Received 4 June 1974; revised Io July 1974)
}

\begin{abstract}
SUMMARY
Growth of Acetobacter aceti NCIB8554 was inhibited by L-threonine and Lhomoserine. Inhibition was relieved by L-aspartate, L-methionine or L-isoleucine. Aspartokinase was inhibited by L-threonine or L-lysine and concertedly inhibited by the two together. L-Methionine or L-isoleucine reversed the joint inhibition. Homoserine dehydrogenase was inhibited by L-threonine. Acetobacter aceti possesses one aspartokinase and a separate homoserine dehydrogenase. Neither enzyme is subject to repression by amino acids of the aspartate family.
\end{abstract}

\section{INTRODUCTION}

Growth of many organisms is inhibited by common metabolites (Ingram \& Jensen, I973; Rittenberg, 1969); study of this inhibition may provide useful information about the regulation of metabolism.

In the biosynthesis of the aspartate family of amino acids in bacteria, the two primary points of control are aspartokinase (AK) and homoserine dehydrogenase (HSD) (Cohen, 197I). The syntheses of lysine, methionine, threonine and isoleucine are affected by control of AK, whilst those of the last three are also influenced by control of HSD (Cohen, I97I).

In Escherichia coli $\mathrm{KI} 2$ there are three separately regulated AK isoenzymes, two of which also carry HSD activity (Cohen, 197I) but many other procaryotes have AK and HSD as single separate enzymes; the AK is then subject to concerted feedback inhibition by two of the end products of the pathway and the HSD is sensitive to threonine (Cohen, Stanier \& Le Bras, 1969).

In this study, the growth inhibition of Acetobacter aceti by threonine and homoserine has been described and the primary regulation of the aspartate family examined.

\section{METHODS}

Growth of organism. Acetobacter aceti $\mathrm{NCIB} 8554$ was grown at $30^{\circ} \mathrm{C}$ with ethanol (I I mM) as the carbon source and ammonium sulphate $(7.6 \mathrm{~mm})$ as the nitrogen source, in a medium buffered with $0.1 \mathrm{M}$-phosphate buffer, $\mathrm{pH} 5.5$, and containing the following salts per litre of distilled water: $\mathrm{MnSO}_{4} .4 \mathrm{H}_{2} \mathrm{O}$, 0.0I $\mathrm{g} ; \mathrm{NaCl}, 0.0 \mathrm{I} \mathrm{g} ; \mathrm{FeCl}_{3}, 0.0 \mathrm{I} \mathrm{g} ; \mathrm{CuSO}_{4} .5 \mathrm{H}_{2} \mathrm{O}, 0.0 \mathrm{I} \mathrm{g}$; $\mathrm{CaCl}_{2} .2 \mathrm{H}_{2} \mathrm{O}$, 0.0I g; $\mathrm{ZnSO}_{4} \cdot 7 \mathrm{H}_{2} \mathrm{O}, 0.0 \mathrm{I} \mathrm{g}$; and $\mathrm{MgSO}_{4} \cdot 7 \mathrm{H}_{2} \mathrm{O}, 0.2 \mathrm{~g}$. The ethanol, buffer and salts were sterilized separately and combined after cooling. Growth experiments were performed in either $25 \mathrm{ml}$ tubes containing $5 \mathrm{ml}$ medium and orbitally shaken at $350 \mathrm{rev}$. $/ \mathrm{min}$ or $500 \mathrm{ml}$ baffled flasks containing $50 \mathrm{ml}$ medium orbitally shaken at $\mathrm{I} 20 \mathrm{rev} . / \mathrm{min}$. The 
growth rates in the two systems were similar. Overnight cultures were used for inoculation and growth was observed by measuring the extinction at $546 \mathrm{~nm}$ using an Eppendorf spectrophotometer (I cm light path). Organisms used for enzyme assays were grown in a fermenter aerated at a rate of $\mathrm{I}$ vol. air/vol. liquid/h and stirred at $1000 \mathrm{rev} . / \mathrm{min}$.

Enzyme preparation. Bacteria suspended in $0.1 \mathrm{M}-\mathrm{K}_{2} \mathrm{HPO}_{4}$ with $0.5 \mathrm{~mm}$-ethylene diamine tetraacetic acid and $3 \mathrm{~mm}$-mercaptoethanol (solution A) were disrupted using a Branson sonifier (Branson Instruments, Inc., U.S.A.) at a power setting of $6 \mathrm{~A}$ for ten $\mathrm{I} 5 \mathrm{~s}$ periods.

The extract was centrifuged at $45000 \mathrm{~g}$ for $10 \mathrm{~min}$ and the supernatant fluid fractionated with ammonium sulphate. The precipitates were collected by centrifugation at $27000 \mathrm{~g}$ for I5 min, suspended in solution A, and dialysed against this solution.

Enzyme assays. AK (ATP:L-aspartate 4-phosphotransferase, EC. 2.7.2.4) was assayed by the method of Truffa-Bachi \& Cohen (I970). HSD (L-homoserine:NADP ${ }^{+}$oxidoreductase, EC. I.I.I.3) was assayed by the method of Datta \& Gest (I970). Enzyme units are defined as that amount of enzyme giving rise to I $\mu$ mol DL-aspartic acid $\beta$-hydroxamate $/ \mathrm{h}$ (AK), or I $\mu \mathrm{mol}$ reduced NADP/min (HSD). Specific activities are expressed as enzyme units/mg protein. Protein was measured by the Biuret method (Layne, 1957).

Column chromatography. A column $(30 \times 2.8 \mathrm{~cm})$ was packed with the anion exchange cellulose DE52 (Whatman, Carl Bittman, Basel), equilibrated in ro mM-phosphate buffer pH 7.5 containing 5 mM-potassium aspartate and 2 mM-ethylene diamine tetraacetic acid. A 20 to $80 \%(w / v)$ ammonium sulphate preparation of the crude extract was applied to the column and eluted with the buffer and a $\mathrm{KCl}$ gradient $(0 \cdot \mathrm{I}$ to I.O $\mathrm{M})$. Fractions $(9 \mathrm{ml})$ were collected and assayed for the two enzymes as described above and for protein by measuring the extinction at $280 \mathrm{~nm}$.

Uptake experiments. A $2.5 \mathrm{ml}$ portion of exponentially growing bacteria $\left(E_{546 \mathrm{~nm}}^{1 \mathrm{~cm}}=0.25\right.$; $56 \mu \mathrm{g}$ dry wt $/ \mathrm{ml}$ ) were added to $\mathrm{L}-\left[\mathrm{U}-{ }^{14} \mathrm{C}\right]$ threonine (specific activity $208 \mathrm{mCi} / \mathrm{mM}$ ) giving a final threonine concentration of $2 \mu \mathrm{M}$. Samples $(0.25 \mathrm{ml})$ were taken, filtered $(0.45 \mu \mathrm{m}$ pore size) and washed four times with $2.5 \mathrm{ml}$ growth medium $\left(30^{\circ} \mathrm{C}\right)$. The filters were placed in vials and dried. Scintillation fluid (Io $\mathrm{ml}$ ) containing $4 \mathrm{~g}$ 2,5-diphenyloxazol (PPO) and $250 \mathrm{mg}$ 2,2'-p-phenylen-bis-(4-methyl-5-phenyloxazol) (dimethyl-POPOP)/1 toluene was added to each vial and the samples counted using a Beckman LS-250 counter system. Threonine uptake was linear over the Io min period tested. The counting efficiency was about $80 \%$.

Chemicals. The L-isomers of amino acids were used throughout except for diaminopimelic acid which was a mixture of LL, DD and meso isomers. Methionine, lysine, isoleucine, homoserine and threonine were obtained from Fluka, Buchs, Switzerland; monosodium aspartate and diaminopimelic acid from Sigma; ATP, NAD and NADP from Boehringer, Mannheim, Germany; PPO and dimethyl-POPOP from Merck, Darmstadt, Germany. L- $\left[\mathrm{U}-{ }^{14} \mathrm{C}\right]$ threonine was obtained from New England Nuclear Corp., Boston, U.S.A.

\section{RESULTS}

\section{The effect of the aspartate family of amino acids on growth}

Acetobacter aceti was grown with aspartate, homoserine, threonine, diaminopimelic acid, lysine, methionine or isoleucine, at concentrations ranging from 0.1 to $20 \mathrm{mM}$. Only threonine and homoserine inhibited growth. Threonine inhibited completely at I mM but had no significant effect at $0.4 \mathrm{~mm}$. Homoserine was only slightly inhibitory at $\mathrm{I} \mathrm{mm}$ but inhibited completely at Io mM.

Methionine $(0.2 \mathrm{mM})$, aspartate $(5 \mathrm{mM})$ or isoleucine $(5 \mathrm{mM})$ prevented inhibition if added 


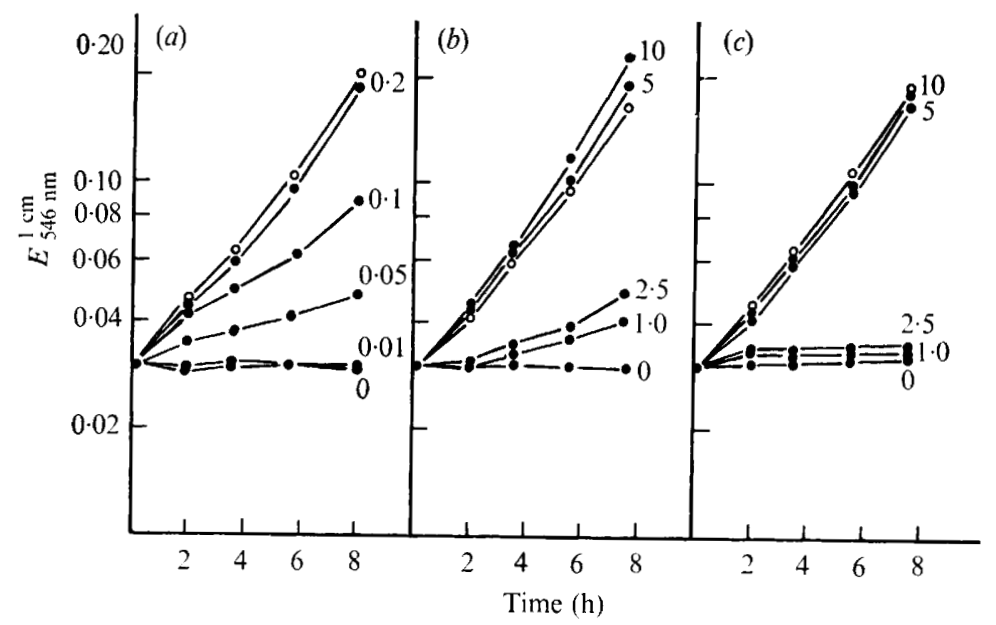

Fig. I. The effect of $(a)$ methionine, $(b)$ aspartate and $(c)$ isoleucine in preventing the growth inhibition of $A$. aceti by I mm-threonine. $\bigcirc$, Control without threonine; $\odot$, cultures containing I mmthreonine; numbers refer to $\mathrm{mm}$ concentrations of $(a)$ methionine, $(b)$ aspartate and $(c)$ isoleucine.

to cultures at the same time as I mM-threonine (Fig. I). If added $2.5 \mathrm{~h}$ after the threonine, methionine (IO $\mathrm{mM})$, aspartate $(50 \mathrm{mM})$ or isoleucine $(40 \mathrm{mM})$ restored the growth rate to near that of uninhibited controls after a lag of about $2 \mathrm{~h}$; lower concentrations took longer. Lysine or diaminopimelic acid had no effect.

Each amino acid of the aspartate family was tested at Io mM concentration for its effect on the growth inhibition caused by $5 \mathrm{~mm}$-homoserine. Aspartate, isoleucine or methionine prevented inhibition, lysine and diaminopimelic acid did not.

\section{Uptake of threonine}

The rate of threonine uptake by $A$. aceti was $295 \mathrm{pmol} / \mathrm{min} / \mathrm{mg}$ dry wt and was unaffected by methionine, isoleucine or aspartate at concentrations 200 times that of the threonine.

\section{Separation of $A K$ and $H S D$}

When a crude extract was fractionated with ammonium sulphate most of the AK sedimented between 20 and $40 \%$ (w/v) saturation whilst HSD sedimented between 40 and $60 \%$ $(w / v)$ saturation (Fig. $2 a$ ). The two enzymes were also separated by ion-exchange chromatography (Fig. 2b), the HSD being eluted before the AK. The threonine sensitivity of AK in each of the $5 \%(\mathrm{w} / \mathrm{v})$ ammonium sulphate fractions was the same.

\section{Enzyme inhibition}

AK was assayed in the 20 to $40 \%(\mathrm{w} / \mathrm{v})$ ammonium sulphate fraction in the presence of each of the amino acids of the aspartate family ( $\mathrm{I}$ to $20 \mathrm{~mm}$ ); all combinations of two amino acids, each Io mM, were also tested. Only lysine, threonine or both together inhibited enzyme activity (Fig. 3). Threonine at ro mM caused $90 \%$ inhibition and $10 \mathrm{~mm}$-lysine inhibited by about $33 \%$, but in combination, only I mM-lysine and $0.3 \mathrm{~mm}$-threonine were needed to give $90 \%$ inhibition. Methionine and isoleucine stimulated enzyme activity slightly; homoserine and diaminopimelic acid had no effect (Fig. 3). The inhibition caused 

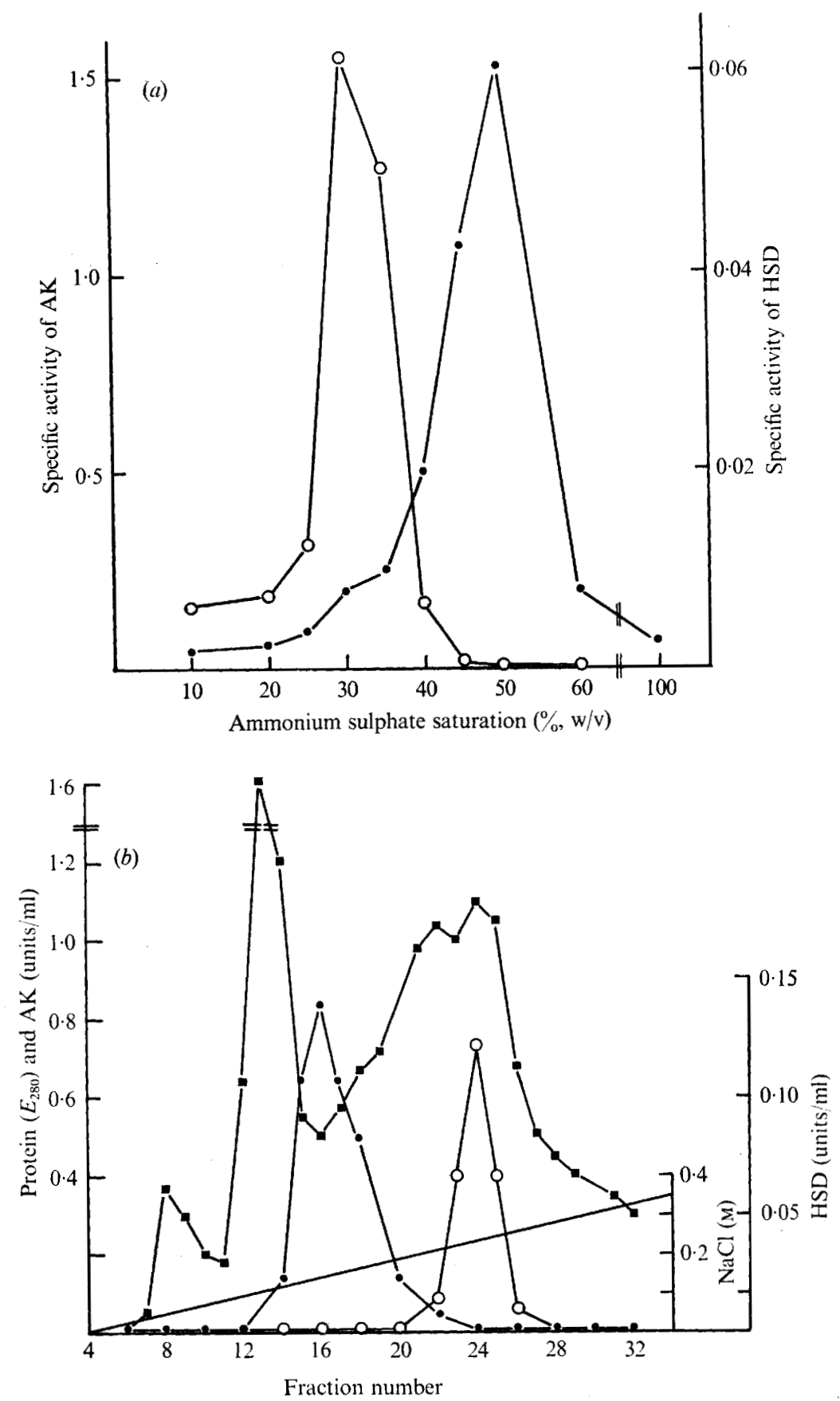

Fig. 2. The separation of AK and HSD (a) by ammonium sulphate fractionation and (b) by ion exchange chromatography (each fraction contained $9 \mathrm{ml}$ ). $\bigcirc$, AK;, HSD; $\mathbf{m}$, protein. 


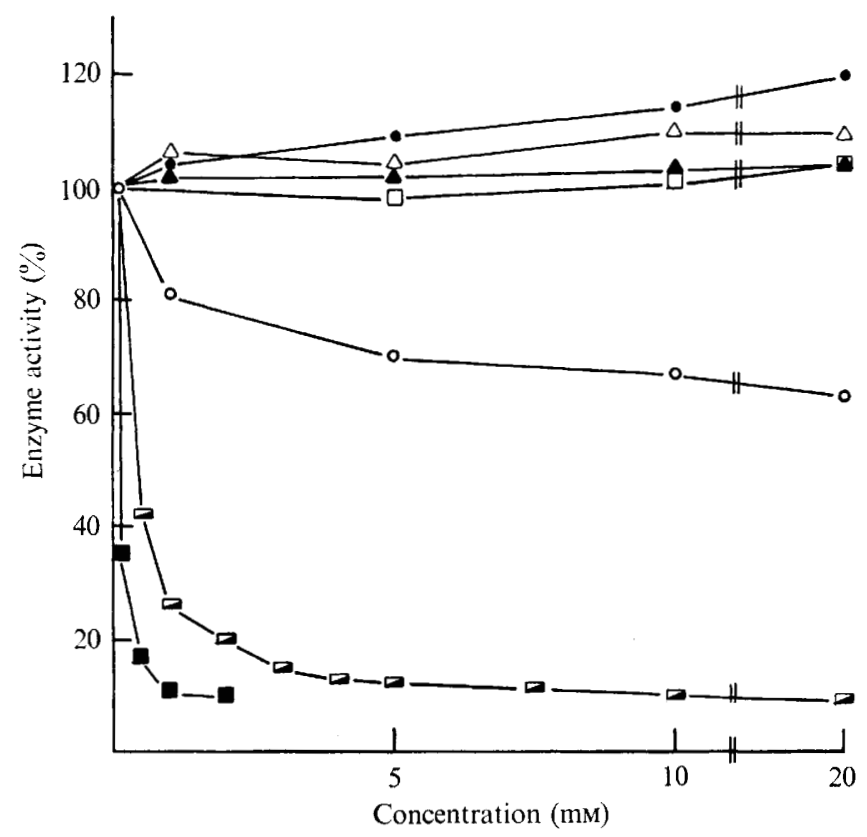

Fig. 3. The effect of amino acids on AK activity in a 20 to $40 \%(w / v)$ ammonium sulphate fraction. $\boldsymbol{O}$, Methionine; $\triangle$, isoleucine; $\boldsymbol{\Delta}$, homoserine; $\square$, diaminopimelic acid; $O$, lysine; $\boldsymbol{\square}$, threonine; a, lysine plus $0.3 \mathrm{~mm}$-threonine.

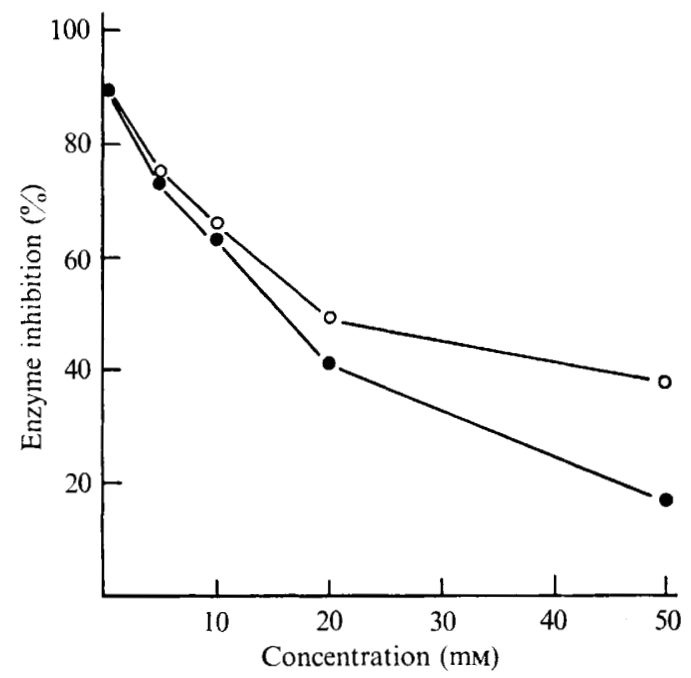

Fig. 4. The effect of methionine and isoleucine on the concerted inhibition of AK by I mm-threonine plus $0 \cdot$ I mm-lysine. $\bigcirc$, Methionine; 0 , isoleucine.

by I mM-threonine plus $0 . \mathrm{I}$ mM-lysine $(90 \%)$ was reduced by increasing concentrations of either methionine or isoleucine (Fig. 4); aspartate was without effect.

Maximal inhibition (60\%) of HSD in the 40 to $60 \%(\mathrm{w} / \mathrm{v})$ ammonium sulphate fraction was reached with Io mM-threonine; no other amino acid of the aspartate family or combinations of two of these affected enzyme activity. The HSD was NADP specific. 


\section{Enzyme repression}

Repression was examined by growing the organism in a fermenter to mid-exponential growth and then taking a control sample. Threonine $(0.5 \mathrm{~mm})$, homoserine $(2 \mathrm{~mm})$ or other test amino acids (IO mM) were added and samples taken 2 and $4 \mathrm{~h}$ later. AK and HSD were measured in dialysed crude extracts and differences of over $20 \%$ from the control were regarded as significant.

AK was not repressed in any of the eight situations tested. The specific activity of the AK increased by 20 and $27 \%$ when aspartate or methionine, respectively, were present in the culture. The AK always displayed the same degree of sensitivity to threonine or threonine plus lysine. HSD decreased to $7 \mathrm{I} \%$ that of the control $2 \mathrm{~h}$ after threonine addition but the specific activity at $4 \mathrm{~h}$ was up to $80 \%$ of the control and the result is not thought to be significant.

\section{DISCUSSION}

The growth inhibition of $A$. aceti 8554 by threonine has been shown to be due to feedback effects on the enzymes of the biosynthetic pathway leading from aspartate. The AK was inhibited by lysine and threonine and concertedly by both, but $100 \%$ inhibition was not found (Fig. 3).

Inhibition of growth by threonine is probably due to a shortage of methionine in the organism, since methionine at very low concentrations prevented growth inhibition (Fig. I $a$ ) and methionine in vitro reduced the concerted feedback inhibition by lysine plus threonine (Fig. 4). Isoleucine is thought to overcome growth inhibition solely by its effect on the concerted inhibition of AK (Fig. 4), thereby allowing the production of methionine to continue. The role of aspartate in overcoming growth inhibition cannot be explained in these terms, nor could any effect on transport be shown. Homoserine inhibited growth but had no effect on AK. Serine and valine also inhibited growth of $A$. aceti 8554, and isoleucine can prevent their inhibition; the serine inhibition is also prevented by methionine or aspartate (O'Sullivan, unpublished results). The growth inhibition by homoserine may, then, have a biochemical basis related to these amino acids.

Acetobacter aceti appeared to possess only one AK and one HSD, as judged by the single peak of activity found by ammonium sulphate fractionation and ion exchange chromatography (Fig. 2) and by the uniform sensitivity of the AK to threonine and to threonine plus lysine in all repression experiments and ammonium sulphate fractions. AK and HSD were not subject to repression by amino acids under the conditions tested. Since HSD was inhibited only weakly by threonine and not at all by any other amino acid of the aspartate family, its importance as a control point in the biosynthesis of threonine, isoleucine and methionine is questionable. The chief regulatory mechanism of the biosynthesis of amino acids of the aspartate family in $A$. acet $i$ seems, therefore, to be the concerted feedback inhibition of the AK.

I am indebted to Professor L. Ettlinger for his sustained interest and advice and to Miss Karin Burvall for technical assistance. This work was supported by research project 3.47I.70 from the Swiss National Science Foundation. 


\section{REFERENCES}

CoHen, G. N. (197I). In Le Métabolisme cellulaire et sa Régulation, pp. I42-144. Paris: Hermann.

Cohen, G. N., Stanier, R. Y. \& Le Bras, G. (I969). Regulation of the biosynthesis of the amino acids of the aspartate family in coliform bacteria and pseudomonads. Journal of Bacteriology 99, 79I-80I.

DAtTA, P. \& GeST, H. (1970). Homoserine dehydrogenase (Rhodospirillum rubrum). In Methods in Enzymology, vol. I7a, p. 703. Edited by H. and C. W. Tabor. New York and London: Academic Press.

INGRAM, L. O. \& JENSEN, R. A. (1973). Growth inhibition by L-phenylalanine in Agmenellum quadruplicatum. A clue to some amino acid interrelationships. Archiv für Mikrobiologie 91, 22 I-233.

LAYNE, E. (1957). Spectrophotometric and turbidometric methods for measuring proteins. III. Biuret method. In Methods in Enzymology, vol. 3, p. 450. Edited by S. P. Colowick and N. O. Kaplan. New York and London: Academic Press.

RitTENBERG, S. C. (1969). The roles of exogenous organic matter in the physiology of chemolithotrophic bacteria. In Advances in Microbial Physiology, vol. 3, pp. I 59-196. New York and London: Academic Press.

Truffa-BACHI, P. \& COHEN, G. N. (I970). Aspartokinase I and homoserine dehydrogenase I (Escherichia coli K12). In Methods in Enzymology, vol. 17a, p. 694. Edited by H. and C. W. Tabor. New York and London: Academic Press. 